\title{
The Effect of Strategy Training on Vocabulary Learning of EFL University Students
}

\author{
Salma Seffar \\ Mohammed $V$ university \\ salma.seffar@um5.ac.ma
}

DOI: $\underline{\text { http://doi.org/10.36892/ijlls.v2i3.356 }}$

\begin{tabular}{ll}
$\begin{array}{l}\text { Received: } \\
\text { 06/07/2020 }\end{array}$ & $\begin{array}{c}\text { Abstract } \\
\text { This study investigated the effect of training in five vocabulary learning }\end{array}$ \\
\hline Accepted: & strategies (VLS) on the vocabulary learning of EFL university students. The \\
$18 / 09 / 2020$ & five vocabulary learning strategies were 'Dictionary Work', 'Word Cards', \\
& 'Semantic Mapping', 'Word Parts', and 'Guessing from Context'. Forty-eight \\
\hline Keywords: & first-year university students, in both the control group (24 students receiving \\
Second language & English language courses) and the experimental group (24 students receiving \\
acquisition; & English language courses besides VLS training) belonging to similar \\
strategies ; $;$ Strategy & proficiency and vocabulary size levels, participated in the study. Data were \\
training & collected utilizing two research instruments namely a vocabulary learning \\
& strategy questionnaire, pre-and post-tests of vocabulary learning ability. The \\
& vocabulary learning strategy questionnaire was used to elicit what types of \\
& vocabulary learning strategies the subjects employed while they learned and \\
& memorized the vocabulary taught independently outside and inside the class. \\
& The pre-test was employed to determine pre-existing knowledge of the \\
& participants. The posttest was administered to identify the impact of \\
vocabulary learning strategy instruction on the students' vocabulary \\
knowledge. Descriptive statistics and t-test showed that after introducing \\
vocabulary learning strategies training (VLST) in class, subjects from the \\
experimental group used more VLS and significantly outperformed subjects of \\
the control group in their ability to learn new words.
\end{tabular}

\section{INTRODUCTION}

Vocabulary is fundamental to language and is of undeniable importance to language learners. Words are the constructing blocks of a language since they tag objects, actions, and ideas without which people cannot convey the intended meaning. Grammatical knowledge does not make for great proficiency in a language. McCarthy(1990) emphasizes that "No matter how well the student learns grammar, no matter how successfully the sounds of L2 are mastered, without words to express a wider range of meanings, communication in an L2 just cannot happen in any meaningful way" (viii). The prominent role of vocabulary knowledge in second or foreign language learning has been recently recognized by theorists and researchers in the field, after a period of relative neglect. Accordingly, numerous types of approaches, techniques, exercises and practices have been introduced into the field to teach vocabulary (Hatch \& Brown, 1995).

The focus of the present study is on vocabulary learning strategies and their instruction within an EFL context. It seeks to investigate the impact of language learning strategy instruction on strategy use and second language vocabulary acquisition of first year university students. This study mainly provides an answer to the question whether vocabulary learning strategy instruction is beneficial in terms of enhanced frequency of use of vocabulary learning strategies and vocabulary knowledge compared to the results in the 
control group where no explicit vocabulary learning strategy instruction will be implemented.

Research Questions:

In line with the objectives outlined above, the present study will attempt to answer the following research questions:

1. What strategies are used by students to acquire new vocabulary in L2, and what is their frequency?

2. Is there a change in vocabulary strategy use after the treatment phase?

3. Is there a difference between the students of the experimental group who have strategy instruction and those in the control group in terms of vocabulary knowledge?

Hypotheses:

This Study seeks to either refute or support the following hypotheses:

1. There will be a low-frequency of vocabulary learning strategy use before the treatment.

2. Vocabulary learning strategy use will increase after the treatment.

3. There will be a positive effect of explicit vocabulary learning strategy instruction on L2 vocabulary acquisition.

\section{LITERATURE REVIEW}

\section{Vocabulary Learning Strategies}

As this study aims to explore the effectiveness of vocabulary learning strategies employed by University students, it is important to clarify the concept of vocabulary learning strategies from different angles. Then, the specific vocabulary learning strategies involved in the present study will be reviewed and discussed.

Vocabulary learning strategies can be considered a subset of general learning strategies which in turn are a subclass of learning strategies in second language acquisition. Interest in learning strategies first developed in the 1970 s with research to identify the characteristics of good language learners (e.g. Naiman, Frohlich et al., 1996). O'Malleyand Chamot(1990) define learning strategies as "the special thoughts or behaviors that individuals use to help them comprehend, learn or retain new information" (p.1). This very broad definition is echoed by Schmitt in defining vocabulary learning strategies. Citing Rubin (1987), Schmitt(1997) says "learning is the process by which information is obtained, stored, retrieved and used . . therefore vocabulary learning strategies could be any which affect this broadly defined process" (p.203). This definition leaves open to question whether vocabulary learning is incidental or deliberate, a factor which has been much debated in the literature. Gu (1997) defines 'vocabulary' as "a dynamic complex of interrelated words' (p.6), and 'learning strategy' as 'a set of deliberate plans and operations a learner employs to facilitate learning processes and boost learning results" (p. 4). In his definition Nation makes clear the intentional character of vocabulary learning and, interestingly, bases his description on the qualities a strategy must possess in order to warrant attention from a teacher. According to Nation, a strategy must:

1- involve choice, that is, there are several strategies to choose from

2- be complex, that is, there are several steps to learn

3- require knowledge and benefit from training

4- increase the efficiency of vocabulary learning and vocabulary use (2001:217).

Because of the huge and hypothetically indeterminate number of vocabulary learning strategies, it will obviously be impossible to attempt an incorporation of all the strategies in the present vocabulary strategy training program. This requires the selection of a subset of strategies which will shape a practical basis for research while also being theoretically 
defensible. Taking this into consideration, the following strategies were selected from Nation's (2001) taxonomy and designated 'crucial' strategies.

Dictionary work (DW)

Although dictionary use is the main feature of most vocabulary instruction, many students do not receive the kind of instruction they need to learn how to use a dictionary effectively (Collier, 1989). Research has shown that students have great difficulty deriving meaning from dictionary definitions (Miller \& Gildea, 1987). Nagy (1997) has shown that much of the problem with definitions was due to their unfamiliar structure. Yet, since other sources of information may be only partial, it is important to know how to use this difficult tool independently (Schatz \& Baldwin, 1986). According to McKeown, et al. (1987), the more students are exposed to dictionary definitions, the better their word learning. The crucial point here is that students receive instruction in how to use what they find in a dictionary entry so that they can translate the cryptic and conventionalized content of definitions into usable word knowledge (Scott \& Nagy, 1997). The instruction can include modeling how to look up the meaning of an unknown word, thinking aloud about various definitions in an entry and deciding which one is the most appropriate definition for a particular context (Graves, 2006). Besides, since students need to expand their knowledge about individual words, they should be encouraged to avail themselves of different kinds of dictionaries. Dictionaries like Thesaurus, Activator and Idiom, especially at advanced levels, can provide them with useful information. Finally, and perhaps most importantly, students should prudentially avoid falling into the pitfall of overusing a dictionary while reading a text. They should not immediately look up every unknown word they encounter in a text rather they should be to some extent reliant on their own guesses based on the sense of the surrounding text.

Word parts (WP)

This strategy is about instruction in morphology. Morphology is one of the most important strategies for learning words. In morphology, students use prefixes, roots, and suffixes within words to derive the meanings of unknown words. Students' ability to use word parts-prefixes, suffixes and roots-to interpret new words can contribute greatly to their vocabulary growth (Anglin, 1993). There are two types of morphology, and undoubtedly both contribute to independent word learning. The first one is the learning of word elements based principally upon ancient Greek and Latin word elements. These word elements include, for example, sur in the word surreptitious and poly in the word polygamy. Research in the field of vocabulary has shown that, in general, learning the meanings of these word elements and how to apply them to derive the meaning of new words is very illuminating and informative as word study (Bauman, 2003). Students should be given practice in using this type of morphology and combining it with context and dictionary clues as independent vocabulary learning strategies.

Guessing from context (GC)

A common L2 vocabulary learning strategy involves inferring a lexeme's meaning from its oral or written context (Haastrup, 1991; cited in Paribakht \& Wesche, 1999). Inferring involves the consideration of graphomorphemic (orthographic), morphological (e.g., roots, stems and affixes), syntactic and semantic qualities; it also entails the use of one's knowledge background (Lee \& Wolf, 1997). The research suggests that beginning L2 readers rely on graphomorphemic correspondences, a bottom-up strategy (Coady \& Huckin, 1997; Lee \& Wolf, 1997). Higher-level learners may be more effective guessers because they possess larger lexicon, which in turn allows them to employ both bottom-up and top-down strategies. Learning vocabulary from context has always been at the top of any vocabulary learning strategies list. It is often seen as something opposed to the direct intentional learning and 
teaching of vocabulary (Kelly, 1990). However, even if learning vocabulary from context should be largely incidental, a deliberate, intentional focus on developing the skills and strategies needed to carry out such learning is required.

Semantic mapping technique (SM)

Semantic mapping involves the building of diagrammatic maps which illustrate how certain word clusters are associated with a keyword, idea or concept. Normally, the new word is placed at the centre of the map and lines or arrows are used to form the nets or webs of related words. Presumably, the visual images can be firmly imprinted in learners' minds. Thus, it may help learners memorize the new word and related ones effectively. This technique was originally developed by Pearson and Johnson (1978) to teach vocabulary to children learning to read in their native language. Morin and Goebel (2001) study the effects of semantic mapping on the acquisition of Spanish L2 vocabulary by English speaking college students. A control group employed a set of vocabulary items in communicative tasks (e.g., small group and pair assignments). The results of the study indicate that the semantic mapping group significantly outperformed the vocabulary activities group in meaning recall and in their ability to organize L2 vocabulary according to thematic relations to other words.

\section{Word cards (WC)}

The activity that can most effectively apply the findings of research on deliberate vocabulary learning is using word cards (Hulstijn, 2001; Mondria \& Mondria-de Vries, 1991; Nation, 2001 ). With word cards, the learner writes a second or foreign language word on one side of an index card and its meaning and other information (e.g. an L1 translation, L2 definition, a typical example, pronunciation, part of speech, common collocates, an illustration, etc.) on the back. The learner then goes through the cards trying to retrieve the meaning, word form or other information from memory. An advantage of word cards over vocabulary notebooks is that the cards can be used more flexibly in conjunction with expanding rehearsal and retrieval. Hulstijn (2001) suggests that the "ideal software program" would combine the database features of a notebook and the drilling potential of word cards while allowing multiple orderings of entries and the establishment of inter-entry linkages.

\section{METHODOLOGY}

The present study seeks to provide an answer to the question whether vocabulary learning strategy instruction is beneficial in terms of enhanced frequency of use of vocabulary learning strategies and vocabulary knowledge compared to the results of the control group where no explicit vocabulary learning strategy instruction is implemented.

\section{Subjects}

The participants in this study are first-year students enrolled at a school of Aerospace Engineering. In this discipline, all subjects are taught in English. Besides, General English courses are a requirement in syllabi. Students receive five hours divided into two sessions of two and three hours per week of General English courses -roughly 60 hours of formal instruction per academic semester. Each student is placed in the appropriate EFL course level based on the results from a placement test that students are given prior to the start of the freshman year. In addition, to ensure homogeneity within groups, during the first two weeks of instruction, EFL teachers are tasked with reevaluating the proficiency level of each student and if necessary, transferring the student to the appropriate level.

The two groups (control and experimental) involved in the present study belong to the upper-intermediate level. They were assumed to have more or less the same proficiency level. They are between 18-20 years old and are males $(\mathrm{N}=23)$ and females $(\mathrm{N}=25)$. The total sample of students who participated in the study is 48 (the experimental group=24 
students and the control group=24). The students in the two groups were assigned the same EFL textbook and teaching materials. The idea was that at the end of the term, students belonging to the same proficiency level should have the same final exam.

\section{Instruments}

To elicit quantitative data from the students, various instruments are used in this study. The first instrument has two sections: 1) a background questionnaire, which aims to obtain some background information about the participants and their English learning experiences, and 2) a student's survey that includes sixty vocabulary learning strategies. The purpose of this questionnaire is to collect demographic information and data about the techniques used by students before and after the treatment and how often do they use them to learn and retain English words. The second instrument is the Vocabulary Levels Test. The scores obtained from the VLT will reflect the learners' current vocabulary level and their homogeneity in terms of vocabulary knowledge. The third instrument is a vocabulary multiple-choice test. It was used twice: first as a pretest to address the issue of pre-existing knowledge and, then, as a posttest to determine the impact of strategy training on the learners' vocabulary performance.

\section{Procedures for data collection}

\section{Pre-experiment}

It is important to make training in strategy use a planned part of a vocabulary development programme. Therefore, the pre-experiment consisted of a planning phase and data collection about the students' strategy use and vocabulary knowledge. Based on Nation's (2001) recommendations for strategy training, the planning involved:

1. Deciding on which strategies to give attention to

2. Deciding how much time to spend on training the learners in strategy use

3. Working out a syllabus for each strategy that covers the required knowledge and provides plenty of opportunity for increasingly independent practice

4. Monitoring and providing feedback on learners' control of strategies

In relation to the data collection part, the procedure started with the background questionnaire filled out by the participants. The questionnaires were distributed to the participants and everything was explained in detail. This part of the research was done on the first week of the term and during the regular class times (a three hours class) in the classrooms and it lasted about 10 minutes. Afterwards, the 50 participants ( 25 female and 23 male students) filled out the vocabulary learning strategies questionnaire. The instructions explained the purpose of the survey and prior to the procedure, the researcher discussed with the respondents' vocabulary learning strategies and made sure that they understood what learning strategies are. The respondents were asked to circle numbers next to each strategy. For example, to circle 1 for never or almost never used this strategy, 2 for occasionally used the strategy, 3 for sometimes used this strategy, 4 for usually and 5 for always. The participants took about 20 minutes to give their responses.

Immediately after turning in the VLSQ, the Vocabulary Levels Test was administered to the participants of the two groups. The instructions were given at the very beginning. For example, the researcher and the teacher of the control group explained to students the benefits of taking the test: they will know their vocabulary size and then be assigned graded readers accordingly. Participants were also shown the way of responding to the questions on the VLT, and asked not to discuss with each other or look up words on dictionaries. It took about 30 minutes on average for participants to complete the VLT. During this class, after a break of fifteen minutes, the pretest was administered and its completion took about 30 minutes.

The questionnaires and the tests were immediately returned to the researcher. In total, 48 valid questionnaires and tests were adopted for data analysis by SPSS. 


\section{Experiment}

Based on the scores of the VLT, both the experimental and control groups were assigned a list of graded readers to improve their vocabulary level. But only the experimental group received explicit instruction on vocabulary learning strategies beginning from the third week of the course. The training was based on Chamot's (1995) CALLA model for strategy training which includes the following steps:

1) Preparation: the purpose of this phase was to help students identify the strategies they are already using and to develop their awareness of the relationship between their strategic processes and effective learning. At this stage, the students were informed about the importance of vocabulary learning strategies and a handout including different strategies was distributed to the students. Concerning vocabulary learning, which was the subject of this study, students with the assistance of the teacher determined specific goals for mastering the vocabulary from certain units of the textbook and the graded readers within a certain time frame.

2) Presentation: in this phase, the teacher modeled the strategy for learners. This implies talking about the characteristics, usefulness, and applications of the strategy explicitly and through examples and illustrations of the strategy concerning unknown vocabularies. Learners were explicitly taught about the multiplicity of strategies to use when they want to remember a word or when they do not know a vocabulary word they encounter in a text and they judge the word to be important to the overall meaning of the text. Furthermore, they received explicit instruction and given a detailed handout on how to use these strategies. They were also informed that no single vocabulary learning strategy would work in every case. A case in point is the word parts strategy (dividing the word into parts) may work with some words but not with others. Also, the use of contextual clues for guessing the meaning of unknown words may be effective in some rich context cases but not in context-reduced texts. For each of the five strategies (dictionary use, word parts, context use, note-taking and word cards), learners spent a total of two hours per strategy spread over several weeks. At this stage, this time was mainly devoted to make learners understand the goal of each strategy, the conditions under which it works well and gain the knowledge needed to use the strategy. Later on, additional time was devoted to strategy practice.

3) Practice: at this stage, students were required to practice the vocabulary learning strategies and the steps involved in each strategy with an authentic learning task. Learners, by the teacher's assistance, applied the strategies in pairs supporting each other. They were asked to make conscious effort to record, learn new vocabulary and to retrieve already acquired vocabulary using a combination of various vocabulary learning strategies. They were also encouraged to examine the effectiveness of their vocabulary coping strategies. For example, this was ensured through activities like guessing from context, dictionary use and word analysis to determine the meaning of unfamiliar words. On the other hand, to recycle already taught vocabulary, students practised the word card strategy or used their notebooks. By the end of this phase, students became more confident about strategy use and able to recognize when one strategy isn't working and how to move on to another.

4) Evaluation: the main objective of this phase was to test learners on strategy use to give them feedback and to give students the chance to evaluate their own success in using learning strategies. Thus, learners developed their metacognitive awareness of their own learning processes. Activities used to develop students self-evaluation included questioning, debriefing discussions after strategies practice, teacher-student interviews, checklists of strategies used, open-ended questionnaires in which students expresses their opinions about the effectiveness of certain strategies, and reports in which students gave accounts about the difficulties and successes in using the strategy inside and outside the classroom. 
5) Expansion: in this final phase students were asked to expand the knowledge they have acquired about vocabulary learning strategies to other domains of language learning and apply them to new contexts. They were encouraged to use the strategies that they found most effective and devise their combinations and interpretations of vocabulary learning strategies.

\section{Post-experiment}

At the end of the term on the last day of the course, both the control group and the experimental group took a vocabulary achievement test (posttest), which covers the target words taught throughout the course. The mean scores of both groups were compared to examine the effects of the training on vocabulary achievement through t-test analysis. The VLSQ was administered to the students of the experimental group again to see any change in strategy use and whether there has been any progress in using strategies and which strategies they used more. The time that was allocated for the completion of the questionnaires and the posttest was determined according to the pilot study results. The responses students gave to each question and the students' scores were entered to the computer for data analyses.

\section{RESULTS}

This part presents the results of the study's quantitative data analysis performed to answer the research questions. First, the results obtained from the Vocabulary Learning Strategy Questionnaire are reported, before and after the treatment. Then, the pre-test and posttest outcomes are presented.

\section{Vocabulary learning strategies use before the treatment}

To answer research question 1: What strategies are used by students to acquire new vocabulary in L2 and what is their frequency? The Vocabulary Learning Strategies Questionnaire (Appendix A) was administered to the students of the experimental group. The Vocabulary Learning Strategy Questionnaire is used in this study not only to reveal whether the participants use the different vocabulary learning strategies listed in the questionnaire but also the frequency of their strategy use. The results of the VLSQ are shown in tables 1 and 2 .

Table 1. Used and unused VLS by the experimental group before strategy training

Used strategies* Unused strategies**

$1,4,5,6,7,10,11,13,14,15,16,19,22,29,2,3,8,9,12,17,18,20,21,23,24,25,26$,

$31,33,37,39,42,43,45,46,49,50,53,54,27,28,30,32,34,35,36,38,40,41,44,47$, $55,57,58,59,60$ $48,51,52,56$

Table 1 shows which strategies are/are not used by the students. The participants' responses to the VLSQ suggest that more than half (31 out of 60) of the vocabulary learning strategies are used. The used strategies include those that received a mean score of 3.0 (sometimes used) and above on a 5-point Likert scale.

To check the frequency of VLS before the training, the sixty strategies were grouped, according to Schmitt's categorization, into two main categories: discovery (from item 1 to 14) and consolidation (from item 15 to 60). Table 2 below presents the descriptive statistics related to the frequency of VLS use before the treatment.

\section{Table 2. Before training VLS descriptive statistics}

\begin{tabular}{l|l|l} 
Categories & Mean & Std. deviation
\end{tabular}




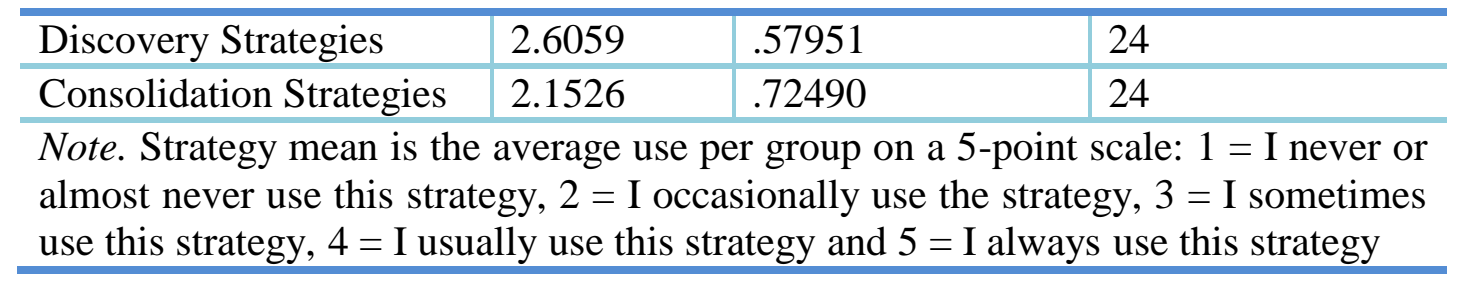

\section{Vocabulary learning strategies after the treatment}

To answer research question 2: Is there a change in strategy use after the treatment phase? The participants of the experimental group were given the VLSQ again. The questionnaire was the same as the one given before the strategy training. As in the previous questionnaires the students were supposed to complete the questionnaires by choosing one of the five items which best corresponds to their vocabulary learning habits.

The questionnaire was evaluated in the same way as the first one that was used before the intervention. The results are presented in tables 3 and 4 .

The participants' responses to the VLSQ suggest that more than half (39 out of 60) of the vocabulary learning strategies are used after strategy training, which suggest a slight increase in VLS use. Table 3 shows which strategies are/are not used by the students. The eight strategies that were not used by the students before the treatment are written in bold.

Table 3. Used and unused VLS by the experimental group after strategy training

\begin{tabular}{ll}
\hline Used strategies* & Unused strategies** \\
\hline $1,2,4,5,6,7, \mathbf{9}, 10,11,13,14,15,16, \mathbf{1 8}$, & $3,8,, 12,17,20,21,, 24,25,26,, 28,30$, \\
$19,22, \mathbf{2 3}, \mathbf{2 7}, 29,31,33,37,39,42,43, \mathbf{4 4}$, & $32,34,35,36,38,40,41,47,51,52$ \\
$45,46, \mathbf{4 8}, 49,50,53,54,55, \mathbf{5 6}, 57,58,59$, & \\
60 &
\end{tabular}

The breakdown of VLSQ after the VLS training reveals an increase at the level of the used strategies. The strategies that students started to use are: $2,9,18,23,27,44,48$, and 56. The used strategies include those that received a mean score of 3.0 (sometimes used) and above on a 5-point Likert scale.

To check the frequency of VLS after the training, the sixty strategies were again grouped, according to Schmitt's categorization, into two main categories: discovery (from item 1 to 14) and consolidation (from item 15 to 60 ). Table 16 below presents the descriptive statistics related to the frequency of VLS use after the treatment.

\begin{tabular}{llll}
\hline Categories & Mean & Std. deviation & N \\
\hline $\begin{array}{l}\text { Discovery } \\
\text { Strategies }\end{array}$ & $\mathbf{3 . 1 5 3 7}$ & $\mathbf{. 4 3 9 5 0}$ & 24 \\
\hline $\begin{array}{l}\text { Consolidation } \\
\text { Strategies }\end{array}$ & $\mathbf{3 . 0 7 7 3}$ & $\mathbf{. 6 5 2 9 1}$ & 24 \\
\hline
\end{tabular}


Note. Strategy mean is the average use per group on a 5-point scale: $1=I$ never or almost never use this strategy, $2=I$ occasionally use the strategy, $3=$ I sometimes use this strategy, $4=$ I usually use this strategy and $5=I$ always use this strategy

Table 4. Post-training VLS descriptive statistics

As the table indicates, the average scores of strategies are higher after the strategy training than the average scores of the strategies before the training. The average scores of both the discovery and consolidation strategies have increased from 2.6059 and 2.1526 to 3.1537 and 3.0773 accordingly. Furthermore, tables 2 and 4 enable comparison of each of the particular strategies before and after the strategy training -participants have started using the strategies they were trained in.

\section{Pre/posttests results}

The main concern of this study is to investigate the effect of vocabulary learning strategy instruction on vocabulary knowledge. To meet this objective, descriptive and inferential statistics were carried out on the pretest and posttest results.

\begin{tabular}{llllllll}
\hline & & Pretest & \multicolumn{5}{c}{ Posttest } \\
\hline Groups & N & Mean & SD & Sig. & Mean & SD & Sig. \\
\hline Experimental & 24 & 15.00 & 5.437 & 0.764 & 36.58 & 2.145 & .000 \\
\hline Control & 24 & 15.46 & 5.056 & 0.764 & 27.04 & 6.925 & .000
\end{tabular}

Table 5. Pre- and post-test results of the experimental and control groups

VLT, Pre- and posttest means of the experimental and control groups are graphically shown in figure 1.

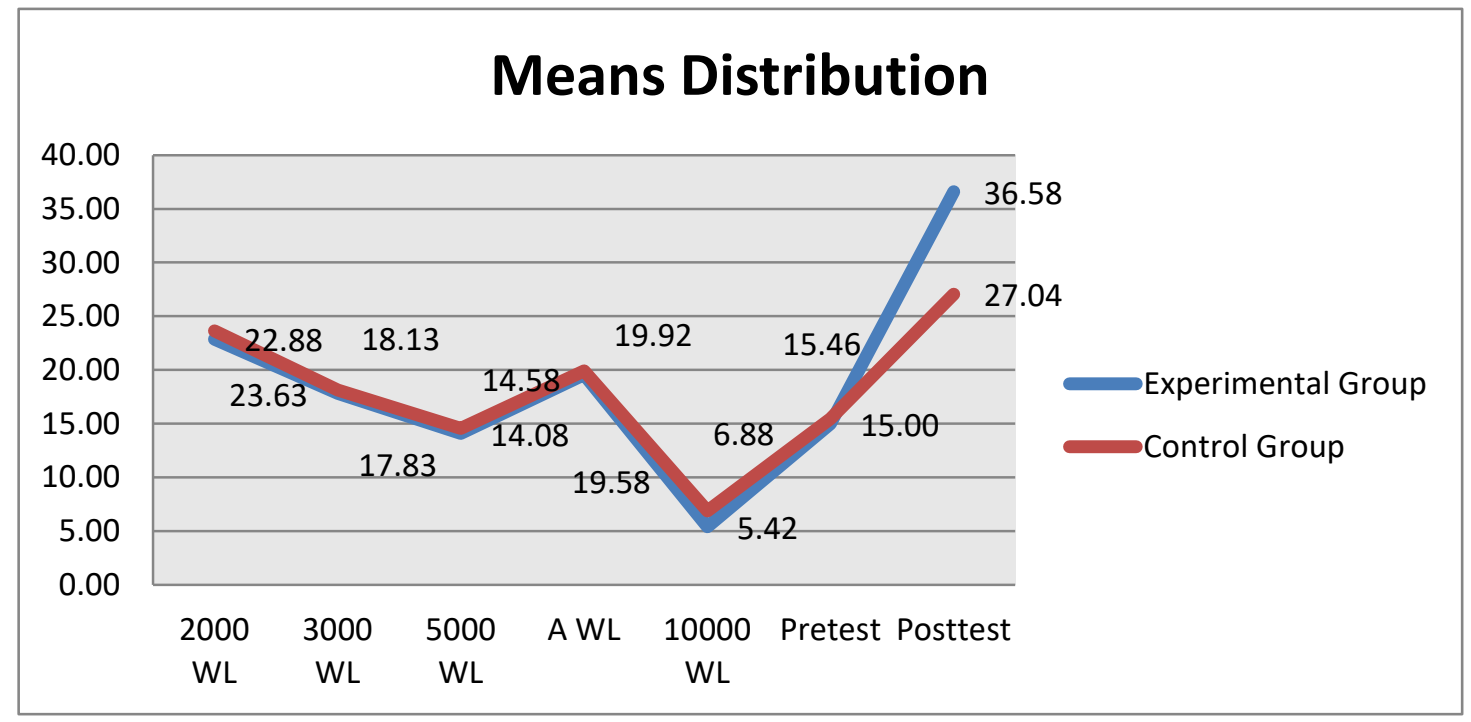

Figure 1: VLT, pre-test and posttest means of the experimental and control groups 
To recap, descriptive statistics and an independent-samples t-test were conducted to compare vocabulary performance in treatment (strategy training) and no treatment conditions. There was a significant difference in the scores for treatment $(\mathrm{M}=36.58$, $\mathrm{SD}=2.145)$ and no treatment $(\mathrm{M}=27.04, \mathrm{SD}=6.925)$ conditions; $\mathrm{t}(46)=6.448, \mathrm{p}=0.000$. In sum, these results suggest that strategy training really does have an effect on vocabulary knowledge. Specifically, the results suggest that when learners receive vocabulary strategy instruction, their memory and knowledge for words increases.

\section{DISCUSSION}

This study focuses on the comparison of the control and the experimental groups in terms of vocabulary knowledge. The results demonstrated clearly that Learners in the experimental group are better in their lexical knowledge after VLST.

Research question one (i.e. What strategies are used by students to acquire new vocabulary in L2 and what is their frequency?) explores the VLS used by the students of the experimental group before receiving the VLST. The results from the VLSQ1 seem to reject the alternative hypothesis as many of the VLS in Schmitt's (1997) taxonomy are popular among the participants of the study even before the intervention. More than half of the strategies (31 out of 60) are claimed to be used by the participants on an average of at least "sometimes". All of these strategies Schmitt categorized as determination, memory or cognitive learning strategies. The fact that these types of learning strategies are familiar among EFL learners is quite expected. Previous research into vocabulary learning strategies (Cohen \& Aphek, 1981; Ahmed, 1989; Gu \& Johnson, 1996; O'Malley, et al., 1985) revealed that many of these strategies, such as memorization strategies, dictionary use, notetaking, and visual and oral repetition are among the most commonly used strategies employed by most L2 learners regardless of gender, language proficiency or cultural background. These results also endorse other research findings (Barcroft, 2009; Kudo, 1999; Lawson \& Hogben, 1996) which suggest that L2 learners prefer the less cognitivelydemanding, mechanical learning strategies notwithstanding their effectiveness.

Another finding from this study is the fact that determination strategies, those used to discover the meaning of unknown words (Nation, 1990; Schmitt, 1997), received the highest mean score among the participants of the study, while consolidation social strategies, those involving social interaction as a means to learn new words, received the lowest among participants. This finding supports Catalán's (2003) conclusion that EFL students tend to focus more on discovering the meaning of unknown words at the expense of spending the time and effort to consolidate the knowledge of those words, especially in a cooperative social environment.

Research question two (i.e. Is there a change in vocabulary strategy use after the treatment phase?) centers on the impact of VLST on VLS use. The results from the VLSQ 2 show the learners' changing use of VLS: the number of the used strategies increased. After being exposed to the VLST in class, the learners of the experimental group increased in their strategy use. Furthermore, they moved from employing shallow strategies to deeper strategies (see table 3). Clearly, the five strategies taught in class had a positive effect on the students' VLS use which is a way better than before the treatment. This improvement comes to support findings from different studies related to VLST and its impact on strategy use. A case in point is Stoffer's (1995) study concluding that strategy instruction was the single best predictor of use of vocabulary learning strategies. Similarly, Hulstijn (1997) cites numerous studies showing gains in successful use of particular strategies following strategy training. Nation (2001) summarizes similar findings for the strategy of guessing from contexts. 
Research question three (i.e. Is there a difference between the students of the experimental group who have strategy instruction and those in the control group in terms of vocabulary knowledge?) focuses on the comparison of the control and the experimental groups in terms of vocabulary knowledge. Since pre-post tests were administered in order to see how learners memorized L2 words and definitions that had been taught in class. The result suggests that the treatment or VLST in class for the experimental group positively affected the learners' ability to memorize the vocabulary task or L2 words taught in class more effectively when compared with the learners in the control group who did not receive VLST. There is improvement of learners (the experimental group) in retaining L2 words compared with those in the control group, $\mathrm{p}=.000$ (see Table 5). The results fits the alternative hypothesis and suggest that after receiving VLST in class learners in the experimental group showed improvement or were better in retaining L2 words and definitions than learners in the control group who did not receive VLST.

Regarding the size of improvement between the two groups, Figure 1, the control group improved by 11.76 points based on the mean scores of 15.64 in the pre-test and 27.4 in the post-test is. The experimental group improved by 21.58 points (the mean score in the pre-test is 15 and in the post-test is 36.5).

As we can see, the post-test scores of the control group improved despite the fact that the learners did not have the VLST in class. Perhaps it can be said that, due to exposure and the nature of the learners' attitude to learning, every learner intends to improve and develop his/her learning. Clearly, the control group did better in the post-test. Nevertheless, the result shows that the post-test score of the control group was lower than that of the experimental group. Presumably, if the control group had received the VLST in class, they could have achieved higher scores in the post-test.

Our result for RQ3 corroborates the findings of previous studies, as stated in Chapter One. Kinoshita (2003:3) cited Cohen and Aphek's (1980) study concerning teaching learners of Hebrew in memory strategies using mnemonic associations (e.g. keyword technique) in order to improve L2 word retention, they found: "better performance in recall tasks occurred when learners formed associations than when associations were not formed". Similarly, the result concerning VLST from an investigation conducted by Avila and Sadoski (1996:379) reveals the positive finding that the experimental group who were taught a single VLS, i.e. the 'Keyword method', outperformed the control group in the recall of L2 words and in comprehension. Clearly, other studies, mentioned in the introduction, related to VLST in the classroom show positive findings and benefit to the L2 learners. However, in fact we rarely find studies involving the training of students in mixed or multiple VLS in the normal classroom.

\section{CONCLUSION}

It was argued that vocabulary is an important ingredient of language and vocabulary learning is an essential part of second or foreign language learning. Language learners need a wide range of target language words to perform effectively both production and comprehension activities in the second and foreign language. One way to help learners boost their L2 vocabulary knowledge is through equipping learners with a wide array of vocabulary learning strategies. The findings of the present study attribute a lot of importance to VLS and especially to training students in those strategies and may have implications for learners, teachers, teacher trainers, and curriculum developers in the field of TEFL in particular and education in general. 


\section{REFERENCES}

Ahmed, M.O. (1989). Vocabulary Learning Strategies. In Meara, P. (Ed.), Beyond Words (pp. 3 14). London: Centre for Information on Language Teaching and Research.

Anglin, J. M. (1993). Vocabulary development: a morphological analysis. Monograph of the Society for Research in Child Development. Cambridge: Cambridge University Press.

Avila, E. and Sadoski, M. (1996). Exploring New Applications of the Keyword Method to Acquire English Vocabulary. Language Learning. 46 (3): 379-395.

Barcroft, J. (2009). Strategies and performance in intentional L2 vocabulary learning. Language Awareness. 18(1): 74-89.

Catalán, R.M.J. (2003). Sex Differences in L2 Vocabulary Learning Strategies. International Journal of Applied Linguistics. 13 (1): 54-77.

Chamot, A.U. (1995). Learning Strategies Instruction in the English Classroom. JALT. 23 (6): 7-9.

Coady, J. and Huckin, T. (eds) (1997). Second Language Vocabulary Acquisition. Cambridge: Cambridge University Press.

Cohen, A.D. and Aphek, E. (1980). Retention of Second Language Vocabulary Overtime: Investigating the Role of Mnemonic Associations. System. 8: 221- 235.

Cohen, A.D. and Aphek, E. (1981). Easifying Second Language Learning. Studies in Second Language Acquisition. 3 (2): 221-236.

Collier, V.P. (1989). How long? A synthesis of research on academic achievement in a second language. TESOL Quarterly. 23(3).

Gu, Y. (1997). Vocabulary Learning Strategies of Good and Poor Chinese EEL Learners. In Bird, N., Falvey, P., Tsui, A., Allison, D. and Mcneill, A. (Eds.), Language and Learning (pp. 376-401). Hong Kong: Government Printer.

Gu, Y. and Johnson, R.K. (1996). Vocabulary Learning Strategies and Language Learning Outcomes. Language Learning. 46 (4): 643-679.

Haastrup, K. (1991). Using Thinking Aloud and Retrospection to Uncover Learners'Lexical Inferencing Procedures. In Færch, C. and Kasper, G. (Eds.), Introspection in Second Language Research (pp.197-12). Clevedon: Philadelphia: Multilingual Matters.

Hatch, E. and Brown, C. (1995). Vocabulary, Semantics, and Language Education. Cambridge: Cambridge University Press.

Hulstijn, J.H. (1997). Mnemonic Methods in Foreign Language Vocabulary Learning: Theoretical Considerations and Pedagogical Implications. In Coady, J. and Huckin,

Hulstijn, J.H. and Laufer, B. (2001). Some Empirical Evidence for the Involvement Load Hypothesis in Vocabulary Acquisition. Language Learning. 51(3): pp. 539-558. 
Kelly, P. (1990). Guessing: No substitute for systematic learning of lexis. System. 18(2): 199-207.

Kudo, Y. (1999). L2 Vocabulary Learning Strategies. Retrieved from http://nflrc.hawaii.edu/NetWorks/NW14/default.html.

Lawson, J.M. and Hogben, D. (1996). The Vocabulary-Learning Strategies of Foreign Language Students. Language Learning. 46 (1):101-135.

Lee, J., \& Wolf, D. (1997). A quantitative and qualitative analysis of the word meaning inferencing strategies of L1 and L2 readers. Spanish Applied Linguistics. 1:24-64.

McCarthy, M. (1990). Vocabulary, Oxford: Oxford University Press.

McKeown, M.G. and Curtis, M.E. (Eds.). (1987). The Nature of Vocabulary Acquisition. Hillsdale, New Jersey: Lawrence Erlbaum Associates.

Miller, G., \& Gildea, P. (1987). How children learn words. Scientific American. 257: 94-99.

Mondria, J.A. and Mondria-De Vries, S. (1991). The Effects of Contextual Richness on the Guessability and the Retention of Words in a Foreign Language. Applied Linguistics. 12 (3) 249-267.

Morin, R. \& Goebel, J. (2001). Basic vocabulary instruction teaching strategies or word? Foreign Language Annals. 34 (1):, -16.

Nagy, W., 1997. On the role of context in first- and second-language vocabulary learning. In Schmitt, N. \& McCarthy, M. (Eds.), Vocabulary: description, acquisition and pedagogy. Cambridge: Cambridge University Press.

Naiman, N., Fröhlich, M., Stern, H.H., and Todesco, A. (1996). The Good Language Learner. Clevedon: Multilingual Matters.

Nation, I.S.P. (1990). Teaching and Learning Vocabulary. Boston: Heinle \& Heinle Publishers.

Nation, I.S.P. (2001). Learning Vocabulary in Another Language. Cambridge: Cambridge University Press.

O’Malley, J.M. and Chamot, A.U. (1990). Learning Strategies in Second Language Acquisition. Cambridge: Cambridge University Press.

O’Malley, M., Chamot, A.U., Stewner-Manzanares, G., Kupper, L., and Russo, R.P. (1985). Learning Strategies Used by Beginning and Intermediate ESL Students. Language Learning. 35 (1): 21-45.

Paribakht, T. S. and Wesche, M. (1999): Reading and incidental L2 vocabulary acquisition: An introspective s tudy of lexical inferencing. Studies in Second Language Acquisition. 21: 195-224.

Pearson, P.D., \& Johnson, D. (1978). Teaching Reading Comprehension. New York: Holt, Rinehart \& Winston. 
Rubin, J. (1987). Learning Strategies: Theoretical Assumptions, Research History and Typology. In Wenden, A. and Rubin, J. (Eds.), Learner Strategies in Language Learning (pp.17-23). Englewood Cliffs: Prentice Hall.

Schatz \& Baldwin (1986) Schatz, E. K., \& Baldwin, R. S. (1986). Context clues are unreliable predictors of word meaning. Reading Research Quarterly. 21(3): 439453.

Schmitt, N. (1997). Vocabulary Learning Strategies. In Schmitt, N. and McCarthy, M. (Eds.), Vocabulary: Description, Acquisition and Pedagogy (pp. 199-227). Cambridge: Cambridge University Press.

Stoffer, I. (1995). University Foreign Language Students' Choice of Vocabulary Learning Strategies as Related to Individual Difference Variables. Unpublished Ph.D. Thesis. University of Alabama, Tuscaloosa. 


\section{Appendix A}

\section{Vocabulary learning strategies questionnaire}

Instructions: For each of the 60 vocabulary learning strategies listed below (items 8 to 67), please state whether you use each strategy: (1) never, (2) occasionally, (3) sometimes, (4) usually, or (5) always by selecting/ticking the appropriate number on your sheet for each item. Approximate completion time: $10 \mathrm{~min}$.

$$
\begin{aligned}
& 1=\text { never or almost never use this strategy } \\
& 2=\text { I occasionally use the strategy } \\
& 3=\text { I sometimes use this strategy } \\
& 4=\text { I usually use this strategy } \\
& 5=\text { I always use this strategy }
\end{aligned}
$$

\begin{tabular}{|c|c|c|c|c|c|}
\hline $\begin{array}{l}\text { A. In order to discover the meaning of an English word I do not know or } \\
\text { recognize... }\end{array}$ & 1 & 2 & 3 & 4 & 5 \\
\hline 8. I analyze the part of the speech (i.e. whether it's a noun, verb, subject, etc.) & & & & & \\
\hline 9. I analyze parts of the word (affixes, roots, etc.) & & & & & \\
\hline $\begin{array}{l}\text { 10. I see if there's a French or an Arabic cognate (e.g. Histoire - } \\
\text { History/coffin-كفن) }\end{array}$ & & & & & \\
\hline 11. I analyze any available pictures or gestures accompanying the word & & & & & \\
\hline 12. I guess the word meaning from context & & & & & \\
\hline 13. I use a bilingual English/Arabic dictionary (hardcopy or on-line) & & & & & \\
\hline 14. I use a monolingual English dictionary (hardcopy or on-line) & & & & & \\
\hline 15. I look it up in a word list & & & & & \\
\hline 16. I look it up in existing flash cards & & & & & \\
\hline 17. I ask the teacher for an Arabic or French translation of the word & & & & & \\
\hline 18. I ask the teacher for an English paraphrase or a synonym of the word & & & & & \\
\hline 19. I ask the teacher for an English sentence that includes the word & & & & & \\
\hline 20. I ask my classmates for the meaning or translation of the word & & & & & \\
\hline 21. I discover the meaning of the word through group work activities & & & & & \\
\hline $\begin{array}{l}\text { B. In order to learn the meaning of an English word (after I find out what } \\
\text { it means)... }\end{array}$ & 1 & 2 & 3 & 4 & 5 \\
\hline $\begin{array}{l}\text { 22. I study and practice word meanings with other students; we quiz each } \\
\text { other }\end{array}$ & & & & & \\
\hline 23. I ask the teacher to check my English words for accuracy & & & & & \\
\hline 24. I try using the word in interactions with native English speakers & & & & & \\
\hline $\begin{array}{l}\text { 25. I study the word with a pictorial representation of its meaning (images, } \\
\text { photos, drawings) }\end{array}$ & & & & & \\
\hline 26. I create my own image of the word's meaning & & & & & \\
\hline 27. I connect the word's meaning to a personal experience & & & & & \\
\hline $\begin{array}{l}\text { 28. I associate the word with its coordinates (e.g. apple with pear, peach, } \\
\text { orange, etc.) }\end{array}$ & & & & & \\
\hline $\begin{array}{l}\text { 29. I connect the word to its synonyms (similar meaning) and antonyms } \\
\text { (opposites) }\end{array}$ & & & & & \\
\hline 30. I use semantic maps (word trees) & & & & & \\
\hline
\end{tabular}




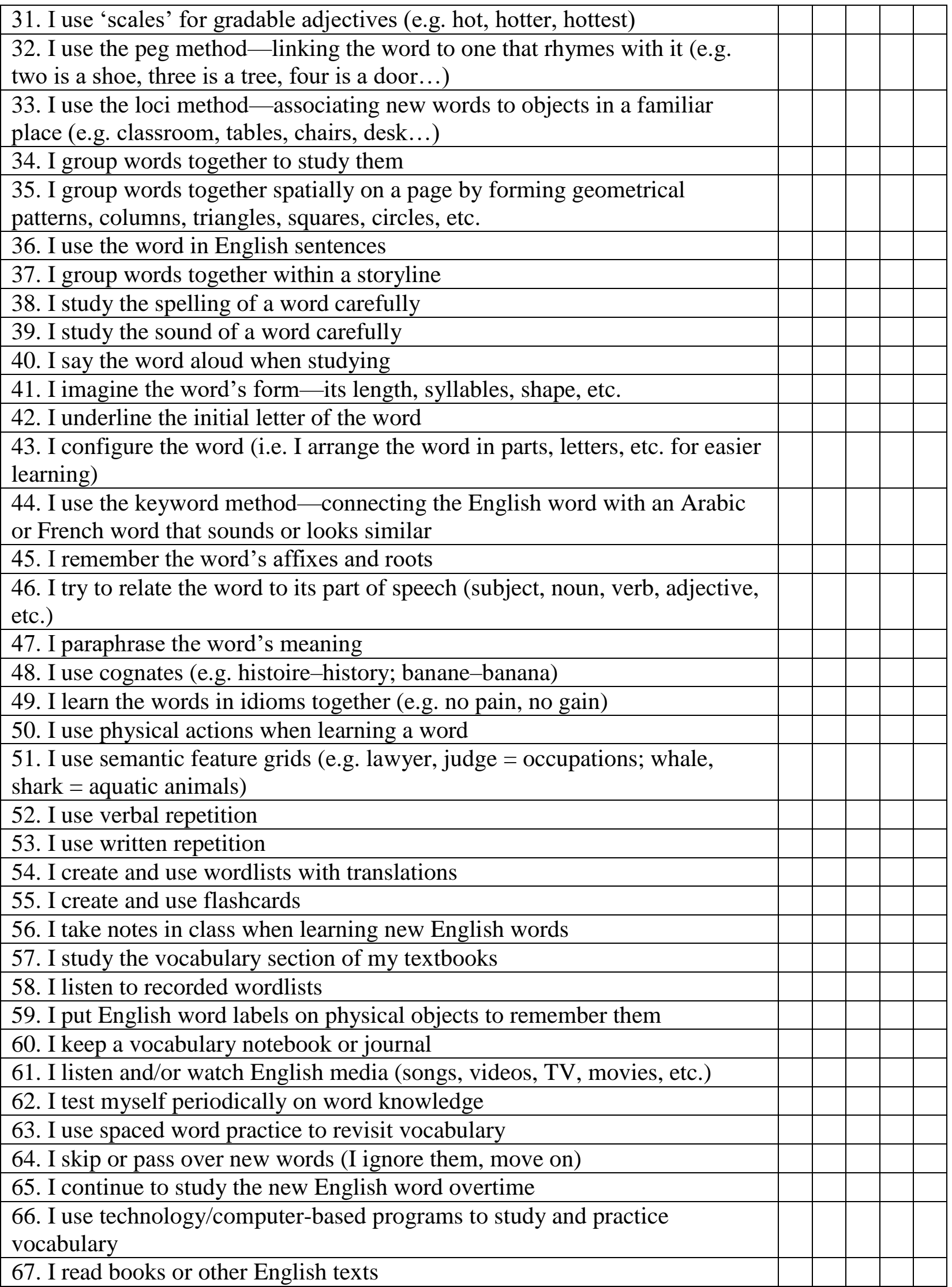

\section{THANK YOU}

